\title{
Effects of controlled hypoglycaemia on cardiac repolarisation in patients with type 1 diabetes
}

\author{
M. L. Koivikko • M. Karsikas • P. I. Salmela • \\ J. S. Tapanainen • A. Ruokonen • T. Seppänen • \\ H. V. Huikuri • J. S. Perkiömäki
}

Received: 26 April 2007 / Accepted: 31 October 2007 / Published online: 19 December 2007

(C) Springer-Verlag 2007

\begin{abstract}
Aims/hypothesis Nocturnal hypoglycaemia may contribute to sudden death in diabetic patients. However, it is not well known why hypoglycaemia makes these patients prone to death.

Methods We assessed the effects of controlled hypoglycaemia on cardiac repolarisation using novel electrocardiographic descriptors of T-wave and QRS complex morphology in 16 type 1 diabetic patients and eight healthy counterparts. Several electrocardiographic variables characterising repolarisation were analysed from digitised 12-lead electrocardiograms during a euglycaemic and a hypoglycaemic clamp.

Results Hypoglycaemia did not result in significant changes either in the QT interval corrected for heart rate by the nomogram method or in QT dispersion. However, the morphology of the T-wave changed significantly during hypoglycaemia. The T-wave amplitude and area in precordial leads decreased significantly in both groups $(p<0.05$ to
\end{abstract}

M. L. Koivikko $\cdot$ P. I. Salmela $\cdot$ H. V. Huikuri $\cdot$

J. S. Perkiömäki $(\square)$

Department of Internal Medicine, University of Oulu,

P.O. Box 5000, (Kajaanintie 50),

90014 Oulu, Finland

e-mail: juha.perkiomaki@oulu.fi

M. Karsikas • T. Seppänen

Information Processing Laboratory of the Technical Department, University of Oulu,

Oulu, Finland

J. S. Tapanainen

Department of Gynecology and Obstetrics, University of Oulu,

Oulu, Finland

\section{A. Ruokonen}

Department of Clinical Chemistry, University of Oulu,

Oulu, Finland $p<0.001$ ). The spatial QRS-T angle (total cosine $\mathrm{R}$ to $\mathrm{T}$ ) $(p<0.05)$ and the height and the width of the T-wave loop ( $p<0.05$ and $p<0.01$, respectively) were also reduced in the diabetic patients. The changes in the repolarisation parameters did not exhibit any significant association with changes in catecholamine levels or in heart rate variability in either group.

Conclusions/interpretation Hypoglycaemia results in distinct alterations in cardiac repolarisation, which may increase the vulnerability to arrhythmic events.

Keywords Electrocardiography · Euglycaemic clamp · Hypoglycaemia · Hypoglycaemic clamp · QRS complex · QRS loop · Repolarisation · T-wave · T-wave loop ·

Type 1 diabetes

\begin{tabular}{|c|c|}
\hline \\
\hline \multicolumn{2}{|c|}{$\begin{array}{l}\text { Abbreviations } \\
\text { ACTH adrenocortice }\end{array}$} \\
\hline $\mathrm{QT}_{\mathrm{c}}$ & $\begin{array}{l}\text { QT interval corrected for heart rate by Bazett's } \\
\text { formula }\end{array}$ \\
\hline $\mathrm{QT}_{\mathrm{Fc}}$ & $\begin{array}{l}\text { QT interval corrected for heart rate by Fridericia's } \\
\text { cubic root formula }\end{array}$ \\
\hline $\mathrm{QT}_{\mathrm{Nc}}$ & $\begin{array}{l}\text { QT interval corrected for heart rate by the } \\
\text { nomogram method }\end{array}$ \\
\hline TCRT & total cosine $\mathrm{R}$ to $\mathrm{T}$ \\
\hline $\mathrm{T}-\mathrm{H}$ & height of the T-wave loop \\
\hline $\mathrm{T}-\mathrm{W}$ & width of the T-wave loop \\
\hline TWLD & T-wave loop dispersion \\
\hline
\end{tabular}

\section{Introduction}

In 1991, Tattersall and Gill, introduced the term 'dead in bed syndrome' [1] for the sudden and unexpected death of 
young people with type 1 diabetes. The pathophysiological background of nocturnal sudden death remained something of an enigma. Nocturnal hypoglycaemia may play an important role, but it is not well understood how hypoglycaemia itself affects the cardiac electrical properties predisposing the individual to sudden arrhythmic death. Roles for the autonomic nervous system and its effects on cardiac repolarisation have been proposed [2].

Observational and experimental studies have demonstrated that hypoglycaemia results in a prolonged QT interval and an increased QT dispersion in healthy individuals and in patients with type 1 and type 2 diabetes [3-9]. This may partly explain the proarrhythmic effects of hypoglycaemia. The assessment of changes in cardiac repolarisation by measurements of the QT interval or QT dispersion is subject to many methodological biases, such as inaccuracies of QT heart rate correction formulas and intersubject variability in the measurement of QT dispersion [10,11]. Therefore, novel repolarisation analyses have been developed to evaluate the characteristics of cardiac repolarisation with greater accuracy. New descriptors of T-wave morphology and the spatial QRS-T angle have already been shown to have better prognostic values than QT interval or QT dispersion with regard to cardiac events in several populations [12-16] and increased complexity of ventricular repolarisation measured by principal component analysis of T-wave morphology has been found to distinguish patients with congenital long QT syndrome from unaffected participants [17, 18]. Therefore, we decided to study the effects of controlled insulininduced hypoglycaemia on the T-wave loop and the QRS complex loop in type 1 diabetic patients and age-matched non-diabetic control participants.

\section{Methods}

Study participants Sixteen type 1 diabetic patients (seven men, nine women) aged $32 \pm 8($ mean $\pm \mathrm{SD}$ ) years (range 18-46 years) and eight healthy participants (three men, five women) aged $34 \pm 10$ (mean \pm SD) years (range $22-48$ years) participated in the study. The known duration of diabetes was 13 years (range 2-29 years) and glycaemic control was fairly strict (mean $\mathrm{HbA}_{1 \mathrm{c}} 7.0 \%$, range 5.8-8.7\%). The patients and healthy participants were all of normal body weight [BMI $23.2 \pm 1.7$ (mean \pm SD) $\mathrm{kg} / \mathrm{m}^{2}$ vs $24.1 \pm 2.3$ (mean $\pm \mathrm{SD}$ ) $\mathrm{kg} / \mathrm{m}^{2}$, respectively]. None of the participants had a previous history of cardiovascular disease or any clinical evidence of heart disease and all had normal ECGs. There were no signs of diabetic complications, with the exception of non-proliferative and treated proliferative retinopathy. Furthermore, there was no clinical evidence of neuropathy and all bed-side autonomic tests (Valsalva, deep breathing and orthostatic test) were within the normal range $[19,20]$. The study protocol was approved by the local Ethics Committee of Oulu University Hospital and all the patients and healthy participants signed informed consent forms approved by the Ethics Committee.

Protocol Both euglycaemic and hypoglycaemic clamp procedures were performed at intervals of at least 1 week in a random order as described in detail earlier [21]. The influences of the present experiments on cardiovascular autonomic regulation have been published earlier [21]. The study participants arrived in the laboratory in the morning after an overnight fast. The diabetic patients had taken their last subcutaneous insulin injection before bedtime and did not administer their morning insulin dose on the day of the study. They were instructed to avoid hypoglycaemia (symptoms or blood glucose $<3.0 \mathrm{mmol} / \mathrm{l}$ ) during the preceding $24 \mathrm{~h}$ and to eat a light snack if their bedtime glucose values were $<6.0 \mathrm{mmol} / \mathrm{l}$. In the morning of the study day, a cannula was inserted into an antecubital vein of the left arm for infusion of glucose and insulin. A second cannula was placed into a large vein on the right forearm for blood sampling. The hand and forearm were placed in a heated box $\left(45^{\circ} \mathrm{C}\right)$ to ensure arterialisation of venous blood. The RR-interval was measured continuously with a real-time microprocessorbased QRS detection system (Polar Electro, Kempele, Finland). The RR-interval recorder was connected to the patient via two dermal electrodes. At every glucose level, a 12-lead ECG was recorded with a paper speed of $50 \mathrm{~mm} / \mathrm{s}$. Blood pressure was measured from the finger of the left hand using the Finapres finger-cuff method (Finapres 2300; Ohmeda, Eaglewood, CO, USA). Blood samples were taken for analyses of blood glucose, serum potassium and counterregulatory hormones. Hypoglycaemic symptoms were registered using a symptom questionnaire, which listed 11 different symptoms: tremor, heart-pounding, nervousness, sweating, tingling, hunger, tiredness, faintness, dizziness, difficulty in thinking and blurry vision. The participants rated the intensity of each symptom from 0 (none) to 10 (severe).

A primed continuous infusion of $80 \mathrm{mU} \mathrm{m}^{-2} \mathrm{~min}^{-1}$ of regular human insulin (Actrapid, Novo Nordisk, Copenhagen, Denmark) was started and the glucose clamp technique was used to adjust the blood glucose concentration [22]. Blood glucose was measured at 2.5 to $5 \mathrm{~min}$ intervals. The study participants were blinded to the blood glucose concentration throughout the study. The glucose concentration was initially stabilised between 4.5 and $5.5 \mathrm{mmol} / 1$. During the hypoglycaemic clamp, blood glucose was permitted to slowly decrease to the first target level of 3.0 to $3.5 \mathrm{mmol} / 1$ (mild hypoglycaemia) and then to the second target level of 2.0 to $2.5 \mathrm{mmol} / \mathrm{l}$ (moderate hypoglycaemia). Thereafter, the glucose concentration was slowly increased and the study was continued at euglycaemia. During the euglycaemic clamp, blood glucose was kept at a level of 4.5 to $5.5 \mathrm{mmol} / \mathrm{l}$ 
throughout, but the measurements were performed four times (similar to the situation during the hypoglycaemic clamp) at regular intervals. All the measurements were performed only after clamping blood glucose in the specified range.

Measurements Biochemical analyses were performed using previously described methods [21]. Blood glucose was analysed at the bedside by the glucose dehydrogenase method (B-Glucose Analyzer; Hemocue, Ängelholm, Sweden). Plasma adrenaline (epinephrine) and noradrenaline (norepinephrine) were determined by high-pressure liquid chromatography. The glucagon, growth hormone, intact adrenocorticotropic hormone (ACTH) and cortisol concentrations were determined by radioimmunoassay as previously reported [21]. Serum potassium was measured with a Cobas Integra automatic analyser using the direct ion-sensitive electrode method (F. Hoffmann-La Roche, Diagnostics Division, Basel, Switzerland).

The duration of the QT interval was measured manually from the paper traces from the beginning of the QRS complex to the clear-cut end of the T-wave obtained from lead V2, with the investigator unaware of the clinical data of the participants. The heart rate-adjusted QT intervals were calculated: (1) according to Bazett's formula $\left(\mathrm{QT}_{\mathrm{c}}\right)$ [23]; (2), as the QT interval corrected for heart rate by Fridericia's cubic root formula $\left(\mathrm{QT}_{\mathrm{Fc}}\right)$ [24]; and (3) as the QT interval corrected for heart rate by the nomogram method $\left(\mathrm{QT}_{\mathrm{Nc}}\right)$ [10]. The QT interval was also measured in every lead of the surface ECG and QT dispersion was calculated using the difference between the maximum and minimum of the QT interval in any of the leads. The ECGs were scanned and digitised using UN-SCAN-IT Graph Digitising System Version 6.0 (Silk Scientific, Orem, UT, USA) [15, 25]. For each ECG, the digital signal of one beat of each lead was used. Several descriptors of T-wave and QRS complex morphology were automatically calculated from the 12-lead ECGs, using a custom-made software application $[15,25]$. The maximum amplitude of the T-wave is defined as the difference between the peak of the T-wave and the baseline. The area of the T-wave is the sum of the voltages deviating from baseline. The software automatically creates T-wave and QRS loops in the Frank's threedimensional space using matrix modification and the singular value decomposition technique. The software calculates the plane where the loop has the maximum first and second dimensions. The loop is rotated until its longest axis is parallel to the $x$-axis. The longest axis of the loop defines its width and the second longest axis perpendicular to the longest axis defines its height. The height/width ratio describes the shape of the loop. The calculated E parameter describes the roughness of the plane, i.e. how well the loop can be adjusted in the plane. Subsequently, a rectangle is adjusted around the loop and divided into 100 subdivisions.
T-wave loop dispersion (TWLD) and QRS loop dispersion are defined as the number of subrectangles traversed by the borderline of the corresponding loop. The total cosine $\mathrm{R}$ to $\mathrm{T}$ (TCRT) is the cosine of the angle between the main vectors of the T-wave loop and the QRS loop in 3dimensional space. It measures the vector deviation between the depolarisation and repolarisation fronts. Small values correspond to large differences in the orientation of the two loops. TCRT may have values from 1 to -1 . The values from 1 to 0 correspond to the angles from $0^{\circ}$ to $90^{\circ}$ and the values from 0 to -1 correspond to the angles from 90 to $180^{\circ}$. Healthy participants usually have TCRT values in the order of 0.4 to 0.8 ; patients with a cardiac disease, such as post-infarction patients, have smaller, often negative values. The repolarisation parameters based on T-wave loop describe morphological aspects in repolarisation, whereas the QT interval is a gross measurement of repolarisation duration.

The analysis of heart rate variability was done with a special software package (Hearts7; Heart Signal, Kempele, Finland). At the steady state of every glucose level, a $15 \mathrm{~min}$ period when no other tests were being performed was selected for the analysis of heart rate variability. The spectral analysis and the quantitative analysis of Poincare plot were performed as described previously [21].

Statistical methods Standard statistical methods were used for the calculation of means and standard deviations. The statistical significance levels of the changes in the variables at the different glucose levels were studied using analysis of variance for repeated measurements. Thereafter, we analysed the statistical significance levels of the contrasts between the values of parameters at baseline and at hypoglycaemia (or between the first and third phase of the experiment during the euglycaemic clamp) for the parameters that differed statistically significantly in the repeated measures analysis. The group of diabetic patients and healthy control persons were combined for assessing the statistical significance of the changes in the unified model and the significance of the differences of the changes between the groups. The two groups were also combined for the statistical analysis of correlations. Results are presented as means \pm SD and Pearson's bivariate correlation coefficients $(r)$.

\section{Results}

The effects of the hyperinsulinaemic clamp on heart rate, $Q T$ intervals, $Q T$ dispersion and T-wave morphology At every glucose level, heart rate was higher in the diabetic patients than in the healthy participants (Tables 1 and 2). During hypoglycaemia, there was a similar increase in the 
Table 1 Effects of hypoglycaemia on QT intervals, QT dispersion and T-wave in a 12-lead electrocardiogram

\begin{tabular}{|c|c|c|c|c|c|c|}
\hline & \multicolumn{6}{|c|}{ Effect per blood glucose range (mmol/1) } \\
\hline & $4.5-5.5$ & $3.0-3.5$ & $2.0-2.5$ & $p$ value $^{\mathrm{a}}$ & $4.5-5.5$ & $p$ value $^{\mathrm{b}}$ \\
\hline \multicolumn{7}{|c|}{ HR (beats per min) } \\
\hline Diabetic & $72 \pm 9$ & $76 \pm 11$ & $80 \pm 11$ & 0.006 & $73 \pm 9$ & 0.003 \\
\hline Control & $59 \pm 5$ & $63 \pm 5$ & $65 \pm 5$ & 0.001 & $58 \pm 5$ & 0.008 \\
\hline $\mathrm{D}+\mathrm{C}$ & $68 \pm 10$ & $71 \pm 11$ & $75 \pm 12$ & & $68 \pm 10$ & $<0.001(<0.001)$ \\
\hline \multicolumn{7}{|l|}{$\mathrm{QT}_{\mathrm{c}}(\mathrm{ms})$} \\
\hline Diabetic & $406 \pm 23$ & $409 \pm 31$ & $419 \pm 35$ & 0.04 & $425 \pm 33$ & 0.004 \\
\hline Control & $416 \pm 33$ & $406 \pm 31$ & $448 \pm 38$ & 0.062 & $435 \pm 29$ & 0.006 \\
\hline $\mathrm{D}+\mathrm{C}$ & $409 \pm 27$ & $408 \pm 31$ & $429 \pm 38$ & & $428 \pm 32$ & $<0.001(0.34)$ \\
\hline \multicolumn{7}{|l|}{$\mathrm{QT}_{\mathrm{Fc}}(\mathrm{ms})$} \\
\hline Diabetic & $398 \pm 27$ & $399 \pm 33$ & $403 \pm 28$ & & $411 \pm 30$ & 0.10 \\
\hline Control & $418 \pm 29$ & $411 \pm 27$ & $440 \pm 43$ & 0.20 & $443 \pm 31$ & 0.046 \\
\hline $\mathrm{D}+\mathrm{C}$ & $404 \pm 28$ & $403 \pm 31$ & $415 \pm 38$ & & $421 \pm 33$ & $0.002(0.04)$ \\
\hline \multicolumn{7}{|l|}{$\mathrm{QT}_{\mathrm{Nc}}(\mathrm{ms})$} \\
\hline Diabetic & $400 \pm 24$ & $405 \pm 34$ & $408 \pm 24$ & 0.18 & $417 \pm 28$ & 0.007 \\
\hline Control & $417 \pm 29$ & $422 \pm 25$ & $440 \pm 48$ & 0.20 & $453 \pm 25$ & 0.053 \\
\hline $\mathrm{D}+\mathrm{C}$ & $406 \pm 26$ & $411 \pm 32$ & $419 \pm 36$ & & $429 \pm 32$ & $<0.001(0.04)$ \\
\hline \multicolumn{7}{|l|}{ QTD (ms) } \\
\hline Diabetic & $41 \pm 15$ & $41 \pm 16$ & $41 \pm 15$ & & $39 \pm 17$ & 0.99 \\
\hline Control & $45 \pm 27$ & $43 \pm 18$ & $51 \pm 20$ & & $40 \pm 19$ & 0.56 \\
\hline $\mathrm{D}+\mathrm{C}$ & $42 \pm 19$ & $41 \pm 16$ & $44 \pm 17$ & & $40 \pm 17$ & $0.61(0.30)$ \\
\hline \multicolumn{7}{|c|}{$\mathrm{T}_{\max } \mathrm{V}_{2}(\mathrm{mV})$} \\
\hline Diabetic & $0.51 \pm 0.27$ & $0.49 \pm 0.28$ & $0.40 \pm 0.32$ & 0.001 & $0.45 \pm 0.29$ & 0.001 \\
\hline Control & $0.48 \pm 0.22$ & $0.50 \pm 0.12$ & $0.23 \pm 0.36$ & 0.03 & $0.46 \pm 0.19$ & 0.008 \\
\hline $\mathrm{D}+\mathrm{C}$ & $0.50 \pm 0.25$ & $0.49 \pm 0.24$ & $0.34 \pm 0.33$ & & $0.45 \pm 0.26$ & $<0.001(0.80)$ \\
\hline \multicolumn{7}{|c|}{$\mathrm{T}_{\max } \mathrm{V}_{5}(\mathrm{mV})$} \\
\hline Diabetic & $0.30 \pm 0.17$ & $0.26 \pm 0.15$ & $0.15 \pm 0.18$ & 0.001 & $0.22 \pm 0.16$ & $<0.001$ \\
\hline Control & $0.37 \pm 0.16$ & $0.34 \pm 0.15$ & $0.10 \pm 0.28$ & 0.003 & $0.36 \pm 0.14$ & $<0.001$ \\
\hline $\mathrm{D}+\mathrm{C}$ & $0.32 \pm 0.17$ & $0.29 \pm 0.15$ & $0.13 \pm 0.21$ & & $0.27 \pm 0.16$ & $<0.001(0.29)$ \\
\hline \multicolumn{7}{|c|}{$\mathrm{T}_{\text {area }} \mathrm{V}_{2}(\mathrm{~s} \times \mathrm{mV})$} \\
\hline Diabetic & $0.50 \pm 0.27$ & $0.49 \pm 0.28$ & $0.38 \pm 0.32$ & 0.001 & $0.44 \pm 0.29$ & 0.001 \\
\hline Control & $0.47 \pm 0.23$ & $0.49 \pm 0.13$ & $0.21 \pm 0.35$ & 0.02 & $0.45 \pm 0.19$ & 0.003 \\
\hline $\mathrm{D}+\mathrm{C}$ & $0.49 \pm 0.26$ & $0.49 \pm 0.24$ & $0.33 \pm 0.34$ & & $0.45 \pm 0.26$ & $<0.001(0.83)$ \\
\hline \multicolumn{7}{|c|}{$\mathrm{T}_{\text {area }} \mathrm{V}_{5}(\mathrm{~s} \times \mathrm{mV})$} \\
\hline Diabetic & $0.29 \pm 0.18$ & $0.25 \pm 0.16$ & $0.13 \pm 0.16$ & 0.001 & $0.20 \pm 0.16$ & $<0.001$ \\
\hline Control & $0.36 \pm 0.17$ & $0.34 \pm 0.15$ & $0.10 \pm 0.28$ & 0.002 & $0.36 \pm 0.15$ & $<0.001$ \\
\hline $\mathrm{D}+\mathrm{C}$ & $0.31 \pm 0.17$ & $0.27 \pm 0.16$ & $0.12 \pm 0.20$ & & $0.26 \pm 0.17$ & $<0.001(0.21)$ \\
\hline
\end{tabular}

Values are means $\pm \mathrm{SD}$

$\mathrm{D}+\mathrm{C}$, diabetic and control participants combined; HR, heart rate; QTD, QT dispersion; $\mathrm{T}_{\text {area }} \mathrm{V}_{2}$, area of T-wave in lead V2; $\mathrm{T}_{\text {area }} \mathrm{V}_{5}$, area of $\mathrm{T}$-wave in lead V5; $\mathrm{T}_{\max } \mathrm{V}_{2}$, maximum amplitude of $\mathrm{T}$-wave in lead V2; $\mathrm{T}_{\max } \mathrm{V}_{5}$, maximum amplitude of T-wave in lead V5

${ }^{a}$ Corresponds to the statistical significance of the contrasts between the first and third measurements

${ }^{\mathrm{b}}$ Indicates the statistical significance of the change in the analysis of variance for repeated measurements; the $p$ value in parentheses indicates the statistical significance of the difference in behaviour of the parameter between the diabetic patients and healthy control participants

supine heart rate in both groups (Table 1). The $\mathrm{QT}_{\mathrm{c}}$ interval increased statistically significantly during hypoglycaemia. The subtle increase in $\mathrm{QT}_{\mathrm{Fc}}$ and $\mathrm{QT}_{\mathrm{Nc}}$ during hypoglycaemia did not reach statistical significance. In fact, in the patients with diabetes, $\mathrm{QT}_{\mathrm{Nc}}$ was significantly longer at euglycaemia at the end of the clamp protocol (Table 1). The QT dispersion did not change statistically significantly during hypoglycaemia in either group. There was no statistically significant increase in the QT interval during the euglycaemic clamp procedure irrespective of which heart rate correction formula was used (Table 2).

The shape of the T-wave changed considerably during hypoglycaemia. The area and maximum amplitude of T-wave decreased markedly, particularly in precordial chest leads (Table 1). Flattened T-waves were also observed during euglycaemia but this change was less marked (Table 2). 
Table 2 QT intervals, QT dispersion and parameters of T-wave in a 12-lead electrocardiogram during euglycaemic clamp

\begin{tabular}{|c|c|c|c|c|c|c|}
\hline & \multicolumn{6}{|c|}{ Effect per blood glucose range $(\mathrm{mmol} / \mathrm{l})$} \\
\hline & $4.5-5.5$ & $4.5-5.5$ & $4.5-5.5$ & $p$ value $^{\mathrm{a}}$ & $4.5-5.5$ & $p$ value ${ }^{\mathrm{b}}$ \\
\hline \multicolumn{7}{|c|}{ HR (beats per min) } \\
\hline Diabetic & $73 \pm 9$ & $73 \pm 9$ & $72 \pm 9$ & & $74 \pm 9$ & 0.16 \\
\hline Control & $59 \pm 6$ & $58 \pm 6$ & $59 \pm 6$ & & $61 \pm 8$ & 0.18 \\
\hline $\mathrm{D}+\mathrm{C}$ & $69 \pm 10$ & $68 \pm 11$ & $68 \pm 10$ & & $70 \pm 10$ & $0.02(0.003)$ \\
\hline \multicolumn{7}{|l|}{$\mathrm{QT}_{\mathrm{c}}(\mathrm{ms})$} \\
\hline Diabetic & $402 \pm 21$ & $405 \pm 28$ & $410 \pm 31$ & & $409 \pm 29$ & 0.37 \\
\hline Control & $418 \pm 19$ & $418 \pm 37$ & $428 \pm 34$ & & $419 \pm 26$ & 0.77 \\
\hline $\mathrm{D}+\mathrm{C}$ & $407 \pm 22$ & $409 \pm 31$ & $416 \pm 32$ & & $412 \pm 27$ & $0.34(0.20)$ \\
\hline \multicolumn{7}{|l|}{$\mathrm{QT}_{\mathrm{Fc}}(\mathrm{ms})$} \\
\hline Diabetic & $393 \pm 23$ & $395 \pm 27$ & $397 \pm 28$ & & $396 \pm 23$ & 0.78 \\
\hline Control & $415 \pm 21$ & $423 \pm 38$ & $426 \pm 36$ & & $420 \pm 29$ & 0.73 \\
\hline $\mathrm{D}+\mathrm{C}$ & $401 \pm 24$ & $404 \pm 33$ & $407 \pm 33$ & & $404 \pm 27$ & $0.43(0.03)$ \\
\hline \multicolumn{7}{|l|}{$\mathrm{QT}_{\mathrm{Nc}}(\mathrm{ms})$} \\
\hline Diabetic & $401 \pm 24$ & $402 \pm 24$ & $405 \pm 23$ & & $402 \pm 18$ & 0.73 \\
\hline Control & $419 \pm 24$ & $435 \pm 43$ & $427 \pm 33$ & & $422 \pm 25$ & 0.34 \\
\hline $\mathrm{D}+\mathrm{C}$ & $407 \pm 25$ & $413 \pm 35$ & $412 \pm 28$ & & $409 \pm 23$ & $0.19(0.03)$ \\
\hline \multicolumn{7}{|l|}{ QTD (ms) } \\
\hline Diabetic & $33 \pm 14$ & $34 \pm 14$ & $34 \pm 18$ & & $33 \pm 10$ & 0.97 \\
\hline Control & $35 \pm 24$ & $54 \pm 32$ & $46 \pm 27$ & 0.20 & $54 \pm 30$ & 0.03 \\
\hline $\mathrm{D}+\mathrm{C}$ & $34 \pm 18$ & $41 \pm 23$ & $38 \pm 22$ & & $40 \pm 21$ & $0.02(0.09)$ \\
\hline \multicolumn{7}{|c|}{$\mathrm{T}_{\max } \mathrm{V}_{2}(\mathrm{mV})$} \\
\hline Diabetic & $0.51 \pm 0.29$ & $0.50 \pm 0.29$ & $0.50 \pm 0.33$ & & $0.49 \pm 0.31$ & 0.51 \\
\hline Control & $0.46 \pm 0.21$ & $0.41 \pm 0.18$ & $0.41 \pm 0.17$ & & $0.38 \pm 0.27$ & 0.17 \\
\hline $\mathrm{D}+\mathrm{C}$ & $0.49 \pm 0.26$ & $0.46 \pm 0.25$ & $0.47 \pm 0.28$ & & $0.45 \pm 0.29$ & $0.047(0.48)$ \\
\hline \multicolumn{7}{|c|}{$\mathrm{T}_{\max } \mathrm{V}_{5}(\mathrm{mV})$} \\
\hline Diabetic & $0.28 \pm 0.12$ & $0.27 \pm 0.11$ & $0.23 \pm 0.15$ & 0.054 & $0.24 \pm 0.10$ & 0.04 \\
\hline Control & $0.35 \pm 0.10$ & $0.31 \pm 0.13$ & $0.29 \pm 0.13$ & 0.02 & $0.30 \pm 0.12$ & 0.03 \\
\hline $\mathrm{D}+\mathrm{C}$ & $0.30 \pm 0.12$ & $0.28 \pm 0.11$ & $0.25 \pm 0.14$ & & $0.26 \pm 0.11$ & $0.002(0.27)$ \\
\hline \multicolumn{7}{|c|}{$\mathrm{T}_{\text {area }} \mathrm{V}_{2}(\mathrm{~s} \times \mathrm{mV})$} \\
\hline Diabetic & $0.51 \pm 0.30$ & $0.49 \pm 0.29$ & $0.49 \pm 0.34$ & & $0.48 \pm 0.32$ & 0.42 \\
\hline Control & $0.46 \pm 0.21$ & $0.40 \pm 0.18$ & $0.40 \pm 0.19$ & & $0.39 \pm 0.25$ & 0.11 \\
\hline $\mathrm{D}+\mathrm{C}$ & $0.49 \pm 0.26$ & $0.46 \pm 0.25$ & $0.46 \pm 0.29$ & & $0.44 \pm 0.29$ & $0.04(0.52)$ \\
\hline \multicolumn{7}{|c|}{$\mathrm{T}_{\text {area }} \mathrm{V}_{5}(\mathrm{~s} \times \mathrm{Mv})$} \\
\hline Diabetic & $0.27 \pm 0.13$ & $0.24 \pm 0.11$ & $0.22 \pm 0.15$ & 0.03 & $0.22 \pm 0.10$ & 0.03 \\
\hline Control & $0.35 \pm 0.10$ & $0.30 \pm 0.13$ & $0.29 \pm 0.13$ & 0.02 & $0.29 \pm 0.12$ & 0.02 \\
\hline $\mathrm{D}+\mathrm{C}$ & $0.30 \pm 0.12$ & $0.26 \pm 0.12$ & $0.24 \pm 0.14$ & & $0.24 \pm 0.11$ & $0.001(0.19)$ \\
\hline
\end{tabular}

Values are means $\pm \mathrm{SD}$

$\mathrm{D}+\mathrm{C}$, diabetic and control participants combined; HR, heart rate; QTD, QT dispersion; $\mathrm{T}_{\text {area }} \mathrm{V}_{2}$, area of T-wave in lead V2; $\mathrm{T}_{\text {area }} \mathrm{V}_{5}$, area of T-wave in lead V5; $\mathrm{T}_{\max } \mathrm{V}_{2}$, maximum amplitude of T-wave in lead V2; $\mathrm{T}_{\max } \mathrm{V}_{5}$, maximum amplitude of T-wave in lead V5

${ }^{\text {a }}$ Corresponds to the statistical significance of the contrasts between the first and third measurements

${ }^{\mathrm{b}}$ Indicates the statistical significance of the change in the analysis of variance for repeated measurements; the $p$ value in parentheses indicates the statistical significance of the difference in behaviour of the parameter between the diabetic patients and healthy controls

Changes in T-wave loop and QRS loop morphology during the hyperinsulinaemic clamp At hypoglycaemia, the width of the T-wave loop (T-W) decreased statistically significantly both in controls and patients with diabetes (Table 3 ). In the latter, there was a decreasing trend in height of the T-wave loop (T-H) during hypoglycaemia. There were no statistically significant changes in the $\mathrm{T}-\mathrm{H} / \mathrm{T}-\mathrm{W}$ ratio, the roughness of the T-wave loop or the morphology of the QRS loop in either of the study groups during the hypoglycaemic clamp. In the diabetic patients, a non-significant trend towards a decrease in TWLD was seen, but in the healthy controls TLDW remained relatively stable. During hypoglycaemia, the most remarkable change was the statistically significant decrease noted in TCRT in the diabetic patients (Table 3, Fig. 1). Changes in TCRT in the healthy control participants were not statistically significant and we observed a clear trend towards statistically significant differences in the behaviour of TCRT between the patients with diabetes and the control participants during the hypoglycaemic clamp. During the euglycaemic clamp, a small decrease in $\mathrm{T}-\mathrm{W}$ was seen in 
Table 3 Effects of hypoglycaemia on T-wave loop and QRS loop morphology

\begin{tabular}{|c|c|c|c|c|c|c|}
\hline & \multicolumn{6}{|c|}{ Effect per blood glucose range $(\mathrm{mmol} / \mathrm{l})$} \\
\hline & $4.5-5.5$ & $3.0-3.5$ & $2.0-2.5$ & $p$ value $^{\mathrm{a}}$ & $4.5-5.5$ & $p$ value ${ }^{\mathrm{b}}$ \\
\hline \multicolumn{7}{|l|}{$\mathrm{T}-\mathrm{H}$} \\
\hline Diabetic & $0.12 \pm 0.05$ & $0.11 \pm 0.05$ & $0.10 \pm 0.05$ & \multirow[t]{3}{*}{0.089} & $0.09 \pm 0.08$ & 0.02 \\
\hline Control & $0.11 \pm 0.04$ & $0.12 \pm 0.04$ & $0.11 \pm 0.04$ & & $0.11 \pm 0.04$ & 0.66 \\
\hline $\mathrm{D}+\mathrm{C}$ & $0.12 \pm 0.05$ & $0.12 \pm 0.05$ & $0.10 \pm 0.05$ & & $0.10 \pm 0.05$ & $0.22(0.89)$ \\
\hline \multicolumn{7}{|l|}{$\mathrm{T}-\mathrm{W}$} \\
\hline Diabetic & $0.34 \pm 0.15$ & $0.31 \pm 0.14$ & $0.25 \pm 0.14$ & \multirow{3}{*}{$\begin{array}{l}0.002 \\
0.004\end{array}$} & $0.27 \pm 0.14$ & 0.002 \\
\hline Control & $0.38 \pm 0.10$ & $0.34 \pm 0.10$ & $0.28 \pm 0.11$ & & $0.35 \pm 0.10$ & 0.003 \\
\hline $\mathrm{D}+\mathrm{C}$ & $0.35 \pm 0.13$ & $0.32 \pm 0.12$ & $0.26 \pm 0.13$ & & $0.29 \pm 0.13$ & $<0.001(0.45)$ \\
\hline \multicolumn{7}{|l|}{$\mathrm{T}-\mathrm{H} / \mathrm{T}-\mathrm{W}$} \\
\hline Diabetic & $0.40 \pm 0.18$ & $0.39 \pm 0.18$ & $0.42 \pm 0.21$ & & $0.34 \pm 0.20$ & 0.18 \\
\hline Control & $0.29 \pm 0.07$ & $0.38 \pm 0.16$ & $0.40 \pm 0.12$ & & $0.34 \pm 0.14$ & 0.66 \\
\hline $\mathrm{D}+\mathrm{C}$ & $0.37 \pm 0.16$ & $0.39 \pm 0.17$ & $0.42 \pm 0.18$ & & $0.34 \pm 0.18$ & $0.43(0.39)$ \\
\hline \multicolumn{7}{|l|}{ T-E } \\
\hline Diabetic & $0.023 \pm 0.010$ & $0.021 \pm 0.009$ & $0.020 \pm 0.013$ & & $0.016 \pm 0.007$ & 0.17 \\
\hline Control & $0.026 \pm 0.012$ & $0.022 \pm 0.010$ & $0.031 \pm 0.015$ & & $0.017 \pm 0.005$ & 0.14 \\
\hline $\mathrm{D}+\mathrm{C}$ & $0.024 \pm 0.011$ & $0.021 \pm 0.009$ & $0.024 \pm 0.014$ & & $0.016 \pm 0.006$ & $0.02(0.14)$ \\
\hline \multicolumn{7}{|l|}{ TWLD } \\
\hline Diabetic & $41.7 \pm 9.0$ & $38.8 \pm 5.7$ & $33.4 \pm 9.5$ & & $37.9 \pm 12.2$ & 0.055 \\
\hline Control & $39.4 \pm 4.4$ & $36.7 \pm 5.0$ & $37.9 \pm 2.8$ & & $38.3 \pm 3.1$ & 0.52 \\
\hline $\mathrm{D}+\mathrm{C}$ & $41.0 \pm 7.8$ & $38.2 \pm 5.5$ & $34.9 \pm 8.1$ & & $38.0 \pm 10.0$ & $0.24(0.82)$ \\
\hline \multicolumn{7}{|l|}{ QRS-H } \\
\hline Diabetic & $1.02 \pm 0.36$ & $1.01 \pm 0.29$ & $0.92 \pm 0.39$ & & $0.95 \pm 0.40$ & 0.21 \\
\hline Control & $0.85 \pm 0.24$ & $0.97 \pm 0.32$ & $0.97 \pm 0.18$ & & $1.11 \pm 0.23$ & 0.66 \\
\hline $\mathrm{D}+\mathrm{C}$ & $0.97 \pm 0.33$ & $1.00 \pm 0.29$ & $0.93 \pm 0.33$ & & $1.00 \pm 0.35$ & $0.71(0.92)$ \\
\hline \multicolumn{7}{|l|}{ QRS-W } \\
\hline Diabetic & $1.75 \pm 0.40$ & $1.74 \pm 0.41$ & $1.68 \pm 0.61$ & & $1.69 \pm 0.61$ & 0.60 \\
\hline Control & $1.79 \pm 0.29$ & $1.89 \pm 0.48$ & $1.89 \pm 0.43$ & & $1.91 \pm 0.35$ & 0.23 \\
\hline $\mathrm{D}+\mathrm{C}$ & $1.76 \pm 0.36$ & $1.78 \pm 0.43$ & $1.75 \pm 0.56$ & & $1.77 \pm 0.54$ & $0.60(0.84)$ \\
\hline \multicolumn{7}{|c|}{ QRS-H/QRS-W } \\
\hline Diabetic & $0.58 \pm 0.16$ & $0.59 \pm 0.16$ & $0.52 \pm 0.22$ & & $0.54 \pm 0.22$ & 0.15 \\
\hline Control & $0.50 \pm 0.19$ & $0.54 \pm 0.22$ & $0.54 \pm 0.15$ & & $0.59 \pm 0.15$ & 0.88 \\
\hline $\mathrm{D}+\mathrm{C}$ & $0.55 \pm 0.17$ & $0.58 \pm 0.18$ & $0.53 \pm 0.19$ & & $0.56 \pm 0.20$ & $0.61(0.86)$ \\
\hline \multicolumn{7}{|l|}{ QRS-E } \\
\hline Diabetic & $0.21 \pm 0.11$ & $0.20 \pm 0.12$ & $0.22 \pm 0.16$ & & $0.20 \pm 0.16$ & 0.91 \\
\hline Control & $0.19 \pm 0.12$ & $0.17 \pm 0.09$ & $0.24 \pm 0.10$ & & $0.20 \pm 0.08$ & 0.16 \\
\hline $\mathrm{D}+\mathrm{C}$ & $0.20 \pm 0.11$ & $0.19 \pm 0.11$ & $0.23 \pm 0.14$ & & $0.20 \pm 0.14$ & $0.25(0.90)$ \\
\hline \multicolumn{7}{|l|}{ QRSLD } \\
\hline Diabetic & $34.1 \pm 3.3$ & $33.4 \pm 1.7$ & $31.5 \pm 8.8$ & & $31.9 \pm 8.8$ & 0.40 \\
\hline Control & $33.9 \pm 1.2$ & $32.7 \pm 1.7$ & $33.4 \pm 1.7$ & & $33.0 \pm 2.4$ & 0.42 \\
\hline $\mathrm{D}+\mathrm{C}$ & $34.0 \pm 2.8$ & $33.2 \pm 1.7$ & $32.1 \pm 7.2$ & & $32.3 \pm 7.3$ & $0.55(0.88)$ \\
\hline \multicolumn{7}{|l|}{ TCRT } \\
\hline Diabetic & $0.41 \pm 0.41$ & $0.38 \pm 0.41$ & $0.17 \pm 0.44$ & 0.03 & $0.34 \pm 0.40$ & 0.04 \\
\hline Control & $0.67 \pm 0.22$ & $0.61 \pm 0.16$ & $0.43 \pm 0.45$ & & $0.71 \pm 0.10$ & 0.65 \\
\hline $\mathrm{D}+\mathrm{C}$ & $0.49 \pm 0.38$ & $0.45 \pm 0.36$ & $0.26 \pm 0.45$ & & $0.46 \pm 0.37$ & $0.15(0.07)$ \\
\hline
\end{tabular}

Values are means $\pm \mathrm{SD}$

D + C, diabetic and control participants combined; E, roughness of loop; H, height of loop; H/W, ratio of H and W of loop; QRSLD, QRS loop dispersion; W, width of loop

${ }^{a}$ Corresponds to the statistical significance of the contrasts between the first and third measurements

${ }^{\mathrm{b}}$ Indicates the statistical significance of the change in the analysis of variance for repeated measurements; the $p$ value in parentheses indicates the statistical significance of the difference in behaviour of the parameter between the diabetic patients and healthy controls 
Fig. 1 TCRT during hypoglycaemic clamp in patients with diabetes (a) and in control participants (b); TCRT during euglycaemic clamp in patients with diabetes (c) and in control participants (d). TCRT differed statistically significantly between the different phases of the experiment only in patients with diabetes during hypoglycaemic clamp $(p=0.04)$ (a). See text for details. The bars represent $95 \%$ CIs
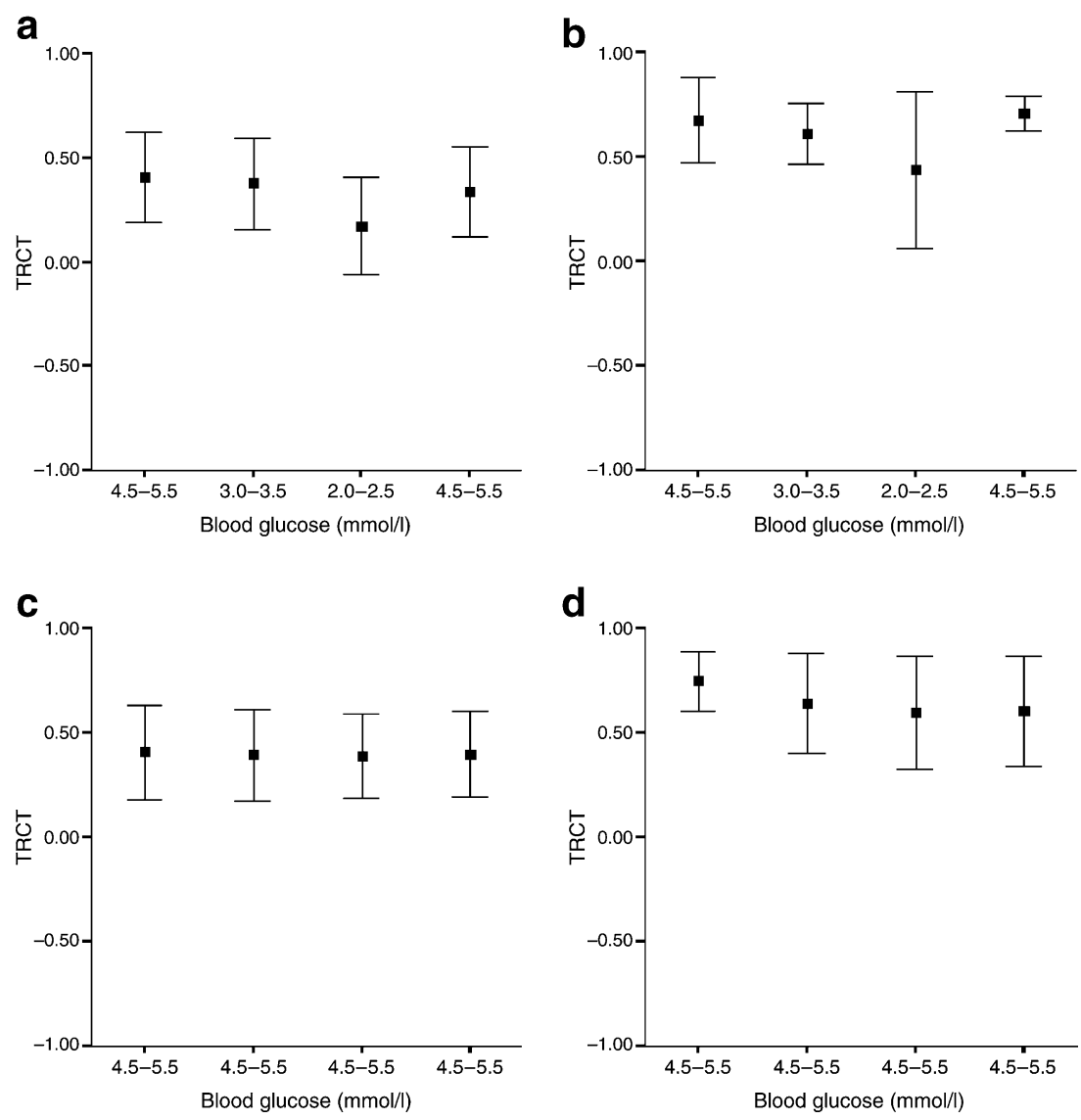

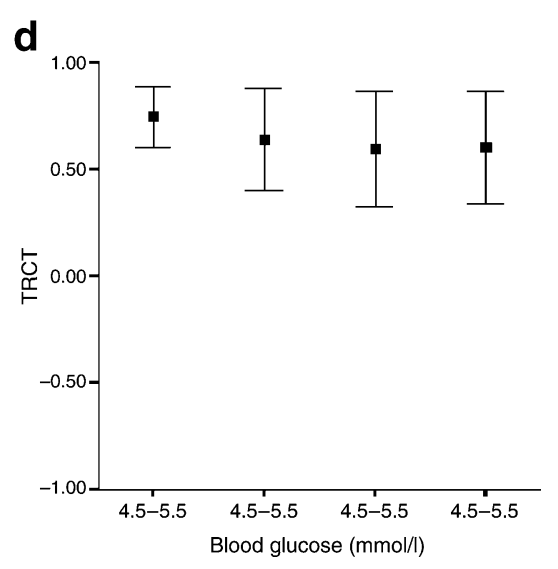

the diabetic subjects; however this change was not statistically significant between the first and third phases of the experiment. We saw no statistically significant changes in the other T-wave loop and/or QRS loop parameters during the euglycaemic clamp in either group (Table 4).

The relationship between the repolarisation variables and the biochemical and heart rate variability parameters during the hyperinsulinaemic clamp In both study groups, the serum concentrations of potassium decreased during the hypoglycaemic and euglycaemic clamp. As expected, the response of the counter-regulatory hormones (glucagon, adrenaline, noradrenaline, cortisol, ACTH, growth hormone) was blunted in the diabetic patients at hypoglycaemia as previously reported [21]. During the euglycaemic clamp, no statistically significant increments in glucagon, adrenaline, noradrenaline or other hormone concentrations were observed in either of the groups. Measures of heart rate variability reflecting cardiac vagal outflow, such as high-frequency spectral component and beat-to-beat heart rate variability, also decreased significantly during hypoglycaemia (results not shown), as previously reported [21].

The change of serum potassium level at hypoglycaemia exhibited a statistically significant relationship with the change of the maximum amplitude of T-wave (V5), but was not statistically significantly associated with the change in $\mathrm{QT}_{\mathrm{Nc}}, \mathrm{T}-\mathrm{W}, \mathrm{T}-\mathrm{H}$ or TCRT (Table 5). No statistically significant associations between the changes in catecholamine levels or heart rate variability and the changes seen in the abovementioned repolarisation parameters were seen (Table 5).

\section{Discussion}

Effects of hypoglycaemia on cardiac repolarisation The present study showed that controlled hypoglycaemia evokes profound changes in cardiac repolarisation, but has no influence on depolarisation. There were three clearly evident changes: (1) a decrease of TCRT, which may reflect the heterogeneity of global cardiac repolarisation; (2) decreases in the height and width of T-wave loop; and (3) an attenuation of T-wave amplitude in precordial leads. The changes in TCRT tended to be even more evident in the diabetic patients than those occurring in their healthy counterparts. The changes in TCRT were not associated with changes in the autonomic regulation of heart rate, sympatho-adrenal activation or changes in the potassium level, suggesting that hypoglycaemia as such also exerts an influence on cardiac repolarisation patterns by other 
Table 4 T-wave loop and QRS complex morphology during euglycaemic clamp

\begin{tabular}{|c|c|c|c|c|c|c|}
\hline & \multicolumn{6}{|c|}{ Effect per blood glucose range $(\mathrm{mmol} / \mathrm{l})$} \\
\hline & $4.5-5.5$ & $4.5-5.5$ & $4.5-5.5$ & $p$ value $^{\mathrm{a}}$ & $4.5-5.5$ & $p$ value $^{\mathrm{b}}$ \\
\hline \multicolumn{7}{|l|}{$\mathrm{T}-\mathrm{H}$} \\
\hline Diabetic & $0.13 \pm 0.06$ & $0.12 \pm 0.06$ & $0.12 \pm 0.07$ & & $0.12 \pm 0.05$ & 0.99 \\
\hline Control & $0.10 \pm 0.03$ & $0.11 \pm 0.04$ & $0.11 \pm 0.03$ & & $0.10 \pm 0.04$ & 0.33 \\
\hline $\mathrm{D}+\mathrm{C}$ & $0.11 \pm 0.05$ & $0.12 \pm 0.05$ & $0.12 \pm 0.06$ & & $0.12 \pm 0.05$ & $0.84(0.32)$ \\
\hline \multicolumn{7}{|l|}{$\mathrm{T}-\mathrm{W}$} \\
\hline Diabetic & $0.33 \pm 0.14$ & $0.32 \pm 0.14$ & $0.31 \pm 0.15$ & 0.16 & $0.29 \pm 0.12$ & 0.035 \\
\hline Control & $0.33 \pm 0.09$ & $0.31 \pm 0.11$ & $0.30 \pm 0.10$ & & $0.30 \pm 0.08$ & 0.059 \\
\hline $\mathrm{D}+\mathrm{C}$ & $0.33 \pm 0.12$ & $0.31 \pm 0.12$ & $0.30 \pm 0.13$ & & $0.29 \pm 0.11$ & $0.002(0.94)$ \\
\hline \multicolumn{7}{|l|}{ T-H/T-W } \\
\hline Diabetic & $0.40 \pm 0.11$ & $0.41 \pm 0.12$ & $0.41 \pm 0.12$ & & $0.44 \pm 0.12$ & 0.27 \\
\hline Control & $0.29 \pm 0.08$ & $0.36 \pm 0.11$ & $0.37 \pm 0.08$ & & $0.35 \pm 0.07$ & 0.14 \\
\hline $\mathrm{D}+\mathrm{C}$ & $0.36 \pm 0.11$ & $0.39 \pm 0.12$ & $0.39 \pm 0.11$ & & $0.41 \pm 0.11$ & $0.052(0.10)$ \\
\hline \multicolumn{7}{|l|}{ T-E } \\
\hline Diabetic & $0.024 \pm 0.009$ & $0.023 \pm 0.009$ & $0.024 \pm 0.009$ & & $0.024 \pm 0.011$ & 0.99 \\
\hline Control & $0.018 \pm 0.006$ & $0.018 \pm 0.005$ & $0.027 \pm 0.014$ & & $0.017 \pm 0.005$ & 0.072 \\
\hline $\mathrm{D}+\mathrm{C}$ & $0.022 \pm 0.008$ & $0.021 \pm 0.008$ & $0.025 \pm 0.011$ & & $0.021 \pm 0.010$ & $0.14(0.18)$ \\
\hline \multicolumn{7}{|l|}{ TWLD } \\
\hline Diabetic & $37.9 \pm 3.4$ & $39.4 \pm 4.8$ & $38.9 \pm 4.9$ & & $38.1 \pm 4.3$ & 0.46 \\
\hline Control & $37.6 \pm 1.3$ & $39.1 \pm 4.5$ & $39.5 \pm 5.4$ & & $38.8 \pm 2.6$ & 0.53 \\
\hline $\mathrm{D}+\mathrm{C}$ & $37.8 \pm 2.8$ & $39.3 \pm 4.5$ & $39.1 \pm 5.0$ & & $38.4 \pm 3.7$ & $0.25(0.91)$ \\
\hline \multicolumn{7}{|l|}{ QRS-H } \\
\hline Diabetic & $0.87 \pm 0.25$ & $0.96 \pm 0.29$ & $0.94 \pm 0.30$ & & $0.96 \pm 0.28$ & 0.077 \\
\hline Control & $0.90 \pm 0.30$ & $1.06 \pm 0.18$ & $1.02 \pm 0.19$ & & $0.91 \pm 0.33$ & 0.29 \\
\hline $\mathrm{D}+\mathrm{C}$ & $0.88 \pm 0.26$ & $1.00 \pm 0.25$ & $0.97 \pm 0.27$ & & $0.94 \pm 0.30$ & $0.052(0.73)$ \\
\hline \multicolumn{7}{|l|}{ QRS-W } \\
\hline Diabetic & $1.77 \pm 0.43$ & $1.76 \pm 0.43$ & $1.78 \pm 0.43$ & & $1.73 \pm 0.37$ & 0.45 \\
\hline Control & $1.85 \pm 0.32$ & $1.81 \pm 0.41$ & $1.81 \pm 0.29$ & & $1.86 \pm 0.24$ & 0.91 \\
\hline $\mathrm{D}+\mathrm{C}$ & $1.80 \pm 0.39$ & $1.78 \pm 0.41$ & $1.79 \pm 0.38$ & & $1.78 \pm 0.33$ & $0.96(0.66)$ \\
\hline \multicolumn{7}{|c|}{ QRS-H/QRS-W } \\
\hline Diabetic & $0.49 \pm 0.09$ & $0.55 \pm 0.13$ & $0.53 \pm 0.11$ & & $0.55 \pm 0.09$ & 0.077 \\
\hline Control & $0.50 \pm 0.18$ & $0.61 \pm 0.17$ & $0.57 \pm 0.09$ & & $0.50 \pm 0.20$ & 0.34 \\
\hline $\mathrm{D}+\mathrm{C}$ & $0.49 \pm 0.13$ & $0.57 \pm 0.15$ & $0.54 \pm 0.10$ & & $0.53 \pm 0.14$ & $0.083(0.77)$ \\
\hline \multicolumn{7}{|l|}{ QRS-E } \\
\hline Diabetic & $0.26 \pm 0.16$ & $0.26 \pm 0.17$ & $0.27 \pm 0.14$ & & $0.29 \pm 0.12$ & 0.84 \\
\hline Control & $0.19 \pm 0.07$ & $0.17 \pm 0.09$ & $0.18 \pm 0.09$ & & $0.15 \pm 0.10$ & 0.60 \\
\hline $\mathrm{D}+\mathrm{C}$ & $0.23 \pm 0.14$ & $0.23 \pm 0.15$ & $0.24 \pm 0.13$ & & $0.24 \pm 0.13$ & $0.97(0.049)$ \\
\hline \multicolumn{7}{|l|}{ QRSLD } \\
\hline Diabetic & $33.4 \pm 2.4$ & $33.2 \pm 1.5$ & $32.7 \pm 2.2$ & & $33.6 \pm 2.9$ & 0.77 \\
\hline Control & $33.1 \pm 1.5$ & $33.0 \pm 1.1$ & $33.4 \pm 1.7$ & & $33.6 \pm 1.4$ & 0.83 \\
\hline $\mathrm{D}+\mathrm{C}$ & $33.3 \pm 2.1$ & $33.1 \pm 1.4$ & $33.0 \pm 2.0$ & & $33.6 \pm 2.4$ & $0.79(0.93)$ \\
\hline \multicolumn{7}{|l|}{ TCRT } \\
\hline Diabetic & $0.40 \pm 0.39$ & $0.39 \pm 0.38$ & $0.38 \pm 0.35$ & & $0.40 \pm 0.35$ & 0.89 \\
\hline Control & $0.74 \pm 0.17$ & $0.64 \pm 0.29$ & $0.59 \pm 0.33$ & & $0.60 \pm 0.32$ & 0.25 \\
\hline $\mathrm{D}+\mathrm{C}$ & $0.53 \pm 0.36$ & $0.48 \pm 0.36$ & $0.46 \pm 0.35$ & & $0.47 \pm 0.35$ & $0.099(0.10)$ \\
\hline
\end{tabular}

Values are means $\pm \mathrm{SD}$

D + C, diabetic and control participants combined; E, roughness of loop; H, height of loop; H/W, ratio of H and W of loop; QRSLD, QRS loop dispersion; W, width of loop

${ }^{a}$ Corresponds to the statistical significance of the contrasts between the first and third measurements

${ }^{\mathrm{b}}$ Indicates the statistical significance of the change in the analysis of variance for repeated measurements; the $p$ value in parentheses indicates the statistical significance of the difference in behaviour of the parameter between the diabetic patients and healthy controls 
Table 5 Correlations between the repolarisation variables and serum potassium, catecholamines and the parameters of heart rate variability

\begin{tabular}{llllll}
\hline & $\Delta$ Potassium & $\Delta$ Adrenaline & $\Delta$ Noradrenaline & $\Delta \log _{\mathrm{e}}(\mathrm{HF})$ & -0.14 \\
\hline$\Delta \mathrm{QT}_{\mathrm{Nc}}$ & -0.15 & 0.34 & 0.11 & 0.17 & -0.26 \\
$\Delta \mathrm{T}_{\max } \mathrm{V}_{5}$ & $0.62^{\mathrm{a}}$ & -0.35 & -0.16 & 0.03 & 0.17 \\
$\Delta \mathrm{T}-\mathrm{W}$ & 0.03 & -0.24 & -0.00 & 0.33 & -0.03 \\
$\Delta \mathrm{T}-\mathrm{H}$ & -0.33 & -0.02 & 0.11 & -0.08 & 0.21 \\
$\Delta \mathrm{TCRT}$ & 0.11 & 0.02 & 0.07 & $\mathrm{O}$ & -0.07 \\
\hline
\end{tabular}

Values are Pearson's correlation coefficients

${ }^{a}$ Indicates the significance of correlation $(p<0.01)$

$\Delta$, changes in a parameter between the third and first measurements; HF, high-frequency spectral component; $\mathrm{T}_{\max } \mathrm{V}_{5}$, maximum amplitude of T-wave in lead V5; SD1, standard deviation of instantaneous beat-to-beat RR-interval variability

mechanisms that are not well understood at present. Only the change in plasma potassium level exhibited a moderate correlation with the T-wave amplitude measured from the precordial leads.

In several previous studies [3-9], a prolonged $\mathrm{QT}_{\mathrm{c}}$ interval and an increased QT dispersion have been reported during hypoglycaemia. According to earlier studies [10], the most often used formula, i.e. Bazett's formula, usually overadjusts the QT interval at high heart rates and undercompensates at low heart rates. Fridericia's equation is superior to Bazett's formula when the heart rate is in the 40 to 120 beats per min range, but it fails at high heart rates as a result of underestimating the QT interval. The nomogram method has been shown to be most accurate in adjusting QT interval at all heart rates [10]. Therefore, we used all three methods since we anticipated that there would be significant changes in heart rate during hypoglycaemia. By using the nomogram method and Fridericia's equation, only non-significant trends towards prolongation of repolarisation were observed. Furthermore, no significant changes were observed in QT dispersion during hypoglycaemia.

These conflicting results with regard to the effects of hypoglycaemia on QT interval and QT dispersion as compared with previous studies may be due to methodological problems in the accurate measurement of the end of the T-wave, particularly during hypoglycaemia. The shape of the T-wave changed markedly, particularly in the precordial chest leads, during hypoglycaemia. The flattened T-waves frequently made the manual measurement of QT interval almost impossible. Consequently, QT interval seems to be an inaccurate variable with poor reproducibility in hypoglycaemia and is clearly not an ideal index for depicting changes in repolarisation caused by hypoglycaemia.

Both $\mathrm{QT}_{\mathrm{c}}$ and $\mathrm{QT}_{\mathrm{Nc}}$ were prolonged during the euglycaemic phase after the hypoglycaemic clamp. This may again be partly due to the more straightforward identification of the end of the T-wave at times when T-waves were no longer flattened. It is also possible that the influence of hypoglycaemia on the QT interval becomes more evident after a certain time delay due to the cardiac memory effect [26]. The existence of this phenomenon will require further experimental evaluation. On the other hand, our study population was relatively small and we did not use highresolution techniques to measure the QT interval. Therefore our method may have been insufficiently sensitive to demonstrate modest increase in the QT interval. However, our observations suggest that morphological changes in cardiac repolarisation may be more significant than prolongation of repolarisation as such during hypoglycaemia.

TCRT has been proposed to describe the heterogeneity in global cardiac repolarisation [27]. This index is not sensitive to subjective definition of the end of the T-wave and is therefore a reproducible and reliable index of cardiac repolarisation. This index was recently described to be a powerful predictor of mortality in various populations [12-16]. TCRT values tended to be more abnormal (smaller) in diabetic patients, even when glucose levels were normal and the abnormality became more marked during hypoglycaemia, suggesting that hypoglycaemia further increases the heterogeneity in global repolarisation. The basic mechanisms of TCRT and its relation to arrhythmia vulnerability are still under investigation and much work is still needed to establish the usefulness of the newer approaches to the measurement of cardiac repolarisation.

We have previously reported that hypoglycaemia results in reduced vagal outflow during the present experiments and that the response of the counter-regulatory hormones is blunted in patients with diabetes during hypoglycaemia [21]. Interestingly, the alterations in cardiac repolarisation reported here were not statistically significantly associated with the changes in cardiac autonomic modulation or in potassium level (excluding T-wave amplitude). This may indicate that heterogeneity of repolarisation and disturbances in cardiac autonomic regulation may independently contribute to vulnerability to arrhythmias during hypoglycaemia; alternatively, it may suggest that hypoglycaemia induces abnormalities in the dynamic relationship between heart rate and repolarisation. Furthermore, the changes in cardiac autonomic nervous and humoral regulation or changes in potassium concentration do not seem to be major determinants of cardiac repolarisation abnormalities during hypoglycaemia. 


\section{Conclusion}

During hypoglycaemia, we observed changes in T-wave loop morphology and TCRT. The changes in TCRT tended to be even more evident among the diabetic patients than the healthy controls. This is in contrast to hormonal responses and responses of the autonomic nervous system to hypoglycaemia, which are usually blunted in diabetic patients compared with healthy participants [28, 29]. Therefore, it is conceivable that hypoglycaemia causes similar, or even more profound changes in the electrical properties of cardiac tissue in diabetic patients than it does in those of healthy participants. These changes may partly explain the vulnerability of these individuals to life-threatening cardiac arrhythmias.

Acknowledgements This study was supported by a research grant from the Finnish Diabetes Research Foundation and by Polar Electro (Kempele, Finland).

Duality of interest The authors declare that there is no duality of interest associated with this manuscript. None of the authors have any financial or other interests in Polar Electro, which supported the study. Polar Electro provided the RR-interval recorders to be used in this research protocol without asking any other feedback from the investigators than the access to the RR-interval data for their internal technical usage.

\section{References}

1. Tattersall RB, Gill GV (1991) Unexplained deaths of type 1 diabetic patients. Diabet Med 8:49-58

2. Weston PJ, Gill GV (1999) Is undetected autonomic dysfunction responsible for sudden death in type 1 diabetes mellitus? The 'dead in bed' syndrome revisited. Diabet Med 16:626-631

3. Marques JLB, George E, Peacey SR et al (1997) Altered ventricular repolarization during hypoglycaemia in patients with diabetes. Diabet Med 14:648-654

4. Landstedt-Hallin L, Englund A, Adamson U, Lins P-E (1999) Increased QT dispersion during hypoglycaemia in patients with type 2 diabetes mellitus. J Intern Med 246:299-307

5. Robinson RTCE, Harris ND, Ireland RH, Lindholm A, Heller SR (2003) Comparative effect of human soluble insulin and insulin aspart upon hypoglycaemia-induced alterations in cardiac repolarization. Br J Clin Pharmacol 55:246-251

6. Robinson RTCE, Harris ND, Ireland RH, Macdonald IA, Heller SR (2004) Changes in cardiac repolarization during clinical episodes of nocturnal hypoglycaemia in adults with type 1 diabetes. Diabetologia 47:312-315

7. Murphy NP, Ford-Adams ME, Ong KK et al (2004) Prolonged cardiac repolarisation during spontaneous nocturnal hypoglycaemia in children and adolescents with type 1 diabetes. Diabetologia 47:1940-1947

8. Robinson RTCE, Harris ND, Ireland RH, Lee S, Newman C, Heller SR (2003) Mechanisms of abnormal cardiac repolarization during insulin-induced hypoglycemia. Diabetes 52:1469-1474
9. Lee SP, Harris ND, Robinson RT et al (2005) Effect of atenolol on QTc interval lengthening during hypoglycaemia in type 1 diabetes. Diabetologia 48:1269-1272

10. Karjalainen J, Viitasalo M, Mänttäri M, Manninen V (1994) Relation between QT intervals and heart rates from 40 to 120 beats/min in rest electrocardiograms of men and a simple method to adjust QT interval values. J Am Coll Cardiol 23:1547-1553

11. Malik M, Acar B, Gang Y et al (2000) QT dispersion does not represent electrocardiographic interlead heterogeneity of ventricular repolarization. J Cardiovasc Electrophysiol 11:835-843

12. Zabel M, Acar B, Klingenheben T, Franz R, Hohnloser SH, Malik M (2000) Analysis of 12-lead T-wave morphology for risk stratification after myocardial infarction. Circulation 102:1252-1257

13. Zabel M, Malik M, Hnatkova K et al (2002) Analysis of T-wave morphology from the 12-lead electrocardiogram for prediction of long-term prognosis in male US veterans. Circulation 105:10661070

14. Kardys I, Kors JA, van der Meer I, Hofman A, van der Kuip D, Witteman JCM (2003) Spatial QRS-T angle predicts cardiac death in general population. Eur Heart J 24:1357-1364

15. Perkiömäki JS, Hyytinen-Oinas M, Karsikas M et al (2006) Usefulness of T-wave loop and QRS complex loop to predict mortality after acute myocardial infarction. Am J Cardiol 97:353360

16. Rautaharju PM, Kooperberg C, Larson JC, LaCroix A (2006) Electrocardiographic predictors of incident congestive heart failure and all-cause mortality in postmenopausal women: the Women's Health Initiative. Circulation 113:481-489

17. Piori SG, Mortara DW, Napolitano C et al (1997) Evaluation of the spatial aspects of T-wave complexity in the long-QT syndrome. Circulation 96:3006-3012

18. Perkiömäki JS, Zareba W, Nomura A, Andrews M, Kaufman ES, Moss AJ (2002) Repolarization dynamics in patients with long QT syndrome. J Cardiovasc Electrophysiol 13:651-656

19. Piha SJ (1991) Cardiovascular autonomic reflex tests: normal responses and age-related reference values. Clin Physiol 11:277-290

20. Ewing DJ, Martyn CN, Young RJ, Clarke BF (1985) The value of cardiovascular autonomic function tests: 10 years experience in diabetes. Diabetes Care 8:491-498

21. Koivikko ML, Salmela PI, Airaksinen KEJ et al (2005) Effects of sustained insulin-induced hypoglycemia on cardiovascular autonomic regulation in type 1 diabetes. Diabetes 54:744-750

22. DeFronzo RA, Tobin JD, Andres R (1979) Glucose clamp technique: a method for quantifying insulin secretion and resistance. Am Physiol 237:E214-E223

23. Bazett HC (1920) An analysis of time relations of electrocardiogram. Heart 7:353-370

24. Fridericia LS (1920) Die Systolendauer im Electrokardiogramm bei normalen Menschen und bei Herzkranken. Acta Med Scand 53:469-486

25. Linna EH, Perkiömäki JS, Karsikas M et al (2006) Functional significance of KCNH2 (HERG) K897T polymorphism of cardiac repolarization assessed by analysis of T-wave morphology. Ann Noninvasive Electrocardiol 11:57-62

26. Patberg KW, Shvilkin A, Plotnikov AN, Chandra P, Josephson ME, Rosen MR (2005) Cardiac memory: mechanisms and clinical implications. Heart Rhythm 2:1376-1382

27. Batchvarov VN, Hnatkova K, Poloniecki J, Camm AJ, Malik M (2004) Prognostic value of heterogeneity of ventricular repolarization in survivors of acute myocardial infarction. Clin Cardiol 27:653-659

28. Bolli GB, Fanelli CG (1999) Physiology of glucose counterregulation to hypoglycemia. Endocrinol Metab Clin North Am 28:467-493

29. Cryer PE (1999) Symptoms of hypoglycemia, thresholds for their occurrence, and hypoglycemia unawareness. Endocrinol Metab Clin North Am 28:495-500 